reestruturação e romper o isolamento, especialmente o isolamento internacional, mas também romper o isolamento da lógica da "categoria", porque não se consegue combater ou negociar a reestruturação simplesmente olhando para aquela fábrica, para aquela empresa sozinha. Também não se consegue fazer nada sem discutir cada fábrica, mas só discutir a fábrica é insuficiente, e só ficar discutindo na categoria é insuficiente.

Para encerrar, uma coisa que também me foi solicitada, discutir as implicações de todo esse processo de reestruturação produtiva do ponto de vista do trabalho e do ponto de vista da psicologia. Eu diria que temos uma porta e temos vocês psicólogos como profissionais. Temos os trabalhadores e os sindicatos e podemos fazer várias coisas com essa porta. Nós podemos fechar, ou podemos continuar a abri-la. Depende de nós mesmos. É uma porta que sempre esteve aberta, mas de fato nunca fomos fundo nela e, em alguns casos até ajudamos a fechar - pensando em termos de estrutura sindical brasileira. Basta olharmos o que aconteceu, por exemplo, com o Diesat (Departamento Intersindical de Estudos e Pesquisas de Saúde e dos Ambientes de Trabalho) ou o que aconteceu e acontece com outros órgãos. Mas a porta está aberta, existe agora, por exemplo, a Unitrabalho (Fundação Interuniversitária de Estudos e Pesquisas sobre o Trabalho), podem existir outros espaços, institucionais ou informais. Mesmo dentro das empresas, aquelas em que acreditamos ser possível fazer um trabalho conjunto com os profissionais que estão lá, tanto na área da psicologia, na engenharia e assim por diante, são uma porta que a gente pode trabalhar para escancarar, para atuar sobre a questão do trabalho.

E não só do ponto de vista da quantidade, que é o que mais tem incomodado o movimento sindical hoje, mas da própria qualidade dos empregos. A nossa proposta, a nossa idéia, é escancarar essa porta prá valer.

\title{
Reestruturação produtiva, sindicalismo e solidariedade
}

Remígio Todeschini ${ }^{16}$

$\mathrm{B}$ om dia para todo mundo. O Bresciani já fez um esquema de toda a questão da reestruturação produtiva, colocando as questões da ação sindical e tentando deixar a porta da psicologia para mim, que também estou aqui querendo aprender com vocês. A minha expectativa é que neste debate abra-se um diálogo entre a universidade e os trabalhadores. O Bresciani também colocou que já existe um trabalho através da rede Unitrabalho - que é a reunião de várias universidades e sindicatos das diferentes centrais que busca estabelecer um trabalho ligado aos problemas do trabalho e dos trabalhadores, então eu acho que nós aqui também seguimos nesse sentido.

Eu queria prosseguir em minha fala sem retomar o que já foi colocado. Os objetivos empresariais, hoje, estão colocados em meio a uma guerra psicológica, à qual estão submetidos os trabalhadores. Pois, do ponto de vista de seus objetivos, os empresários vivem a questão da guerra comercial, a questão da competitividade internacional e querem que nós

${ }^{16}$ Tesoureiro da Central Única dos Trabalhadores (CUT) e diretor do Sindicato dos Trabalhadores na Indústrias Químicas do ABC. 
trabalhemos com mais qualidade, além de promoverem o corte do custo do trabalho, do custo que representam todos os nossos direitos. Não sei se vocês viram, durante os últimos dias, a questão da Vasp, que propôs a redução das tarifas aéreas, o que é bom para nós, até para a CUT, porque dá para viajar melhor. Mas, em contrapartida, o senhor Canhedo, no início do mês passado, fez uma redução nos holerites de $30 \%$. E houve, inclusive, uma movimentação do pessoal do vôo para poder garantir o salário, como está acontecendo hoje a greve dos professores universitários em nível federal, em função também de cortes que o governo quer adotar nas gratificações. Então, na realidade, eu estou apresentando aqui dois aspectos que fazem com que estejamos diante de uma guerra psicológica, inclusive entre nós mesmos, os trabalhadores. Quer dizer, está se estimulando a concorrência entre trabalhadores de indústrias no nível internacional, então, aí vem a troca: "olha eu vou ter, eu tenho de fabricar determinado produto, tenho dez fábricas no mundo, vou ter de fechar cinco e eu vou fechar uma ou outra fábrica dependendo da produtividade que essas fábricas oferecerem". Isso está sendo imposto para nós, se já não bastasse isso, dentro de uma mesma empresa, até pelo sistema da participação nos lucros e nos resultados. O que é? É a discussão dos resultados econômicos de uma empresa, da qual podemos sair com um salário ou meio ou dois ou três salários a mais, a depender da concorrência entre departamentos. No fundo, o que eles chamam de "parceria" é, na verdade, o estabelecimento de uma guerra fratricida entre trabalhadores. É justamente isso que nomeio de "guerra psicológica".

É claro que as conseqüências disso já foram tratadas aqui, dentre elas, o desemprego estrutural frente a essa reestruturação produtiva. Estrutural no sentido de que as estruturas empresariais estão sendo reduzidas. Se não bastasse isso, nós estamos sofrendo também em função da estabilização econômica, o desemprego conjuntural, que é fruto da política econômica recessiva que o governo está adotando, quer dizer, uma política que privilegia as importações para manter a paridade entre o real e o dólar e evidentemente arrebentando ainda mais o emprego no país. E aí vemos na Folha de São Paulo da última sexta-feira a cifra de um milhão e meio de desempregados só em São Paulo. Ou seja, há dois aspectos importantes no que diz respeito ao desemprego: a reestruturação produtiva e a questão conjuntural. Em muitos setores, por exemplo, temos reduções que variam entre 30 e $60 \%$ da mão-de-obra e a tendência é aumentar ainda mais. No setor metalúrgico, a idéia é ter a produção de mais de 3 milhões de carros com basicamente 30\% dos trabalhadores que a gente tinha no início dos anos 80 , de modo que podemos dizer que a reestruturação produtiva ocorre de forma muito violenta no setor metalúrgico.

Acentuando a pressão sofrida pelos trabalhadores, ouvimos o atual ministro do trabalho dizer que temos somente duas opções: se quisermos continuar com o emprego, temos que aceitar a redução salarial. Mas trata-se de redução salarial em um país onde a média salarial é extremamente baixa. Ainda mais quando se exige, para a ocupação dos novos empregos, com salários inferiores a trezentos reais, que a pessoa tenha minimamente o ginásio. Essa é a situação que vivemos hoje. O setor têxtil, por exemplo, é um setor que foi desmantelado aqui na região sudeste e transferido para a região nordeste. Lá, como acontece no Ceará, estão sendo criadas cooperativas de trabalho onde os patrões dessas novas empresas de tecnologia de ponta pagam cento e vinte e sete reais para um trabalhador manejar máquinas de última geração. Isso no nordeste. Evidentemente, o trabalhador com cento e vinte e sete reais não tem condições de se sustentar, em hipótese alguma. Tem de continuar morando na favela.

Um aspecto também importante dos efeitos da reestruturação produtiva, associado à intensificação do ritmo de trabalho, é o número crescente de doenças profissionais. Embora a massa de trabalhadores no setor industrial tenha diminuído, aumentou um pouco o número de trabalhadores no setor de serviços, mas evidentemente este último não absorveu a redução do primeiro. Enquanto a General Motors tinha, no final dos anos 80, setecentos mil trabalhadores espalhados pelo mundo, a Microsoft de Bill Gates tem, no mundo inteiro, 
catorze mil funcionários. Note-se que a Microsoft é uma empresa de ponta do setor de serviços - que é anunciado aos quatro ventos como o grande absorvedor de mão-de-obra. É dito que vamos sair do setor industrial e passar para o setor de serviços, mas, na realidade, isso é uma "balela", porque até o analista de sistemas "está indo para o beleléu", já que hoje em dia os softwares de um computador são fabricados em série e a Microsoft simplesmente os vende em pontos estratégicos em versões para as diferentes línguas e resolve o problema, eliminado também o analista. Assim, não há essa tão falada substituição de empregos do setor industrial pelo setor de serviços.

Vamos para a ação sindical. Na ação sindical, frente a essa perda sistemática de empregos, evidentemente a nossa posição tem sido uma posição de resistência. É evidente que o trabalhador tem consciência de que, se em muitos aspectos as novas tecnologias têm diminuído os ambientes insalubres e perigosos, elas também trazem o problema da não reposição do emprego. O que temos feito, desde o início da década de 90 , são greves em que exigimos a garantia de postos de trabalho, pois não se teve alternativas. Com greves e resistência, conseguimos melhorar os pacotes de demissão.

Melhor foi para os trabalhadores europeus ou americanos que, frente ao processo da reestruturação produtiva, tiveram a saída das aposentadorias antecipadas; pode-se ver isso na Itália, na Espanha, na França, na Suécia. Foram assim minimizados os problemas sociais. No Brasil, entretanto, com esse escancaramento total, o trabalhador passou a engrossar a massa dos excluídos.

A primeira ação é uma ação de resistência pelo emprego. Mas qual é a ação propositiva que temos para oferecer? Essa ação propositiva foi até objeto de discussão da $8^{\text {a }}$ Plenária Nacional da CUT, realizada em 96, durante a qual foram levantados alguns pontos importantes a serem considerados frente a esse processo.

Primeiro, a redução da jornada de trabalho. Não há outra alternativa. Se o patronato ganha em produtividade com a redução do emprego, temos de discutir, na nossa sociedade como um todo, a divisão social do trabalho para tudo. Isso significa, inclusive, aumentar a possibilidade do lazer. A duração da jornada de trabalho foi objeto de campanha recente dos socialistas franceses, que lutavam por uma jornada de trinta e duas horas para o ano 2002. Nossa perspectiva é de termos aqui a redução da jornada para trinta e seis horas.

Segundo, a requalificação profissional. Mas ela não pode ser apenas um adestramento do trabalhador para manejar os novos equipamentos. Temos que preparar os trabalhadores para a cidadania, para a democracia. Mais adiante eu vou comentar sobre o papel do psicólogo nessa questão.

Também é preciso, de um modo geral, fortalecer as políticas sociais públicas, até para poder minimizar o problema da exclusão. Isso significa ampliar a educação pública básica para todos, ampliar a atenção à saúde, pois a rede privada não é a solução. Mesmo na Meca do capitalismo internacional, que é os Estados Unidos, até a sagrada esposa do Bill Clinton propôs, na primeira gestão, que houvesse a mudança do sistema privado para um sistema de previdência social pública. Em relação ao PIB americano, já há um gasto de $20 \%$ em saúde e os serviços privados - até pela não concorrência do setor público e pelos custos com novas tecnologias - tendem a ter um custo cada vez maior.

Outro ponto, que para nós é o mais fundamental, é a necessidade do fortalecimento da solidariedade. Diante da intensa concorrência e da guerra psicológica que se estabelece, o patronato fala em parceria. Mas o problema todo é a concorrência e quem não produzir mais perderá até a fábrica. Há um exemplo recente nosso, lá do Sindicato dos Químicos do ABC. Os dirigentes de um setor da Colgate, que domina 70\% do mercado mundial de dentifrícios, têm cinco fábricas no hemisfério sul e sua estratégia é de transformá-las em apenas duas. Afirmaram que o melhor lugar para uma delas é no $A B C$, por ser um ponto estratégico 
(escoamento de mercadorias pelo porto de Santos etc.), mas vieram ao nosso sindicato para pedir que nos tornássemos um pouco mais bonzinhos para que essa fábrica pudesse ser instalada e permanecesse no ABC. Queriam que isso fosse um estímulo para que houvesse mais produtividade, mais concorrência e mais perdas para os trabalhadores.

Agora, de nossa parte, o que temos a fazer é justamente ampliar a solidariedade internacional entre os trabalhadores, a solidariedade entre as categorias, entre os ramos da produção e a solidariedade principalmente no interior da fábrica, isso é que nós não podemos, em hipótese alguma, perder. Porque, em um país que se denomina civilizado e no qual todos falam aos quatro ventos da necessidade da democracia, só não está existindo democracia no local de trabalho. Todos lutam por isso, quem está na universidade luta para ter o seu grêmio estudantil ou o seu diretório acadêmico. Os professores lutam para poder escolher ao menos o reitor ou selecionar de uma lista o nome menos pior possível. Na fábrica nós não temos oportunidade de ter esse diálogo. Minimamente há o sindicato, que vem do modelo corporativo de Vargas. Esse modelo também nos coloca em uma camisa de força. Vou dar só um exemplo: hoje, para acompanhar setecentas fábricas, no caso do Sindicato dos Químicos do $\mathrm{ABC}$, só temos trinta diretores sindicais, que representam mais de quarenta mil trabalhadores, o que torna humanamente impossível fazer um trabalho de representação. Deveria haver no mínimo a representação no local de trabalho, para podermos enfrentar essa situação. Eu sei que o desafio é grande, porque nós estamos numa guerra, nessa guerra psicológica, nessa guerra ideológica, na qual o patrão coloca para o trabalhador: "Olha, fica bonzinho, você se qualificando vai ganhar um salário melhor etecetera e tal".

No plano internacional, o trabalhador vai continuar lutando pelos seus interesses vitais, então o conflito de classes existe e não é posto por nós, trabalhadores, é posto por quem estimula este tipo de sociedade neoliberal e competitiva que faz com que haja uma concentração cada vez maior de renda. A moda agora é a reestruturação, a competitividade, mas eu me pergunto: será que para o capitalismo isso não vai significar a sua morte, já que os consumidores estão diminuindo? Eu sempre faço essa indagação na hora da negociação, aí sempre pedem para nós: "Olha, vocês têm de oferecer alternativas para baixar o custo", mas o custo da mão-de-obra é o custo menor da produção. No setor automobilístico é de $6 \%$ e no setor petroquímico, que é de ponta, é 3 ou 4\%, é até menor, porque como é um regime de processo contínuo, a produção é muito mais ágil. Mas querem que nós paguemos a conta!

Eu vou pular um ponto aqui, a participação do Estado, em função do tempo e porque eu acho que a expectativa de vocês é saber o que tem a ver a psicologia com a reestruturação produtiva e porque o sindicato vem colocar a colher no meio. Eu só quero dizer o seguinte, os psicólogos, alguns no papel de representantes dos setores de recursos humanos, não devem só se prestar a serem guardiões da redução do custo. Não quero tornar ofensivas essas minhas palavras, eu quero é abrir o debate. Não podemos nos tornar domesticadores dessa realidade da reprodução, da reestruturação produtiva. E aí eu quero colocar uma questão que eu acho fundamental. Vocês devem ter evidentemente estudado a psicologia social... No fundo, devemos trabalhar para que, sobre isso o Bresciani falou muito bem, saibamos como vencer a pressão, o medo, a angústia, a degradação. Vamos vencer isso com uma participação real, com a participação democrática, com o estímulo à cidadania. Acho que nós não temos alternativa se não criar cada vez mais, em todos os locais, quer seja na comunidade, na igreja, nas fábricas, locais de trabalho, espaços de democracia. Eu acho que o psicólogo, para poder vencer esses efeitos, ele tem de trabalhar pela libertação dos oprimidos, usando um pouquinho o Paulo Freire, no sentido de que os trabalhadores ganhem com a democracia e ganhem laços de solidariedade. Essa é a minha exposição inicial, depois vamos para o debate. Obrigado. 